\title{
MEDIA CAPTURE AND LOCAL GOVERNMENT ACCOUNTABILITY
}

\author{
Jiancai $\mathbf{P i}^{*}$
}

\begin{abstract}
:
This paper mainly discusses the effects of media capture on local government accountability in undemocratic countries. Firstly, we construct the models with and without media capture from the perspective of incentive theory. Secondly, we conduct a comparative analysis between the outcomes with and without media capture. The analysis shows that no media capture decreases the local official's equilibrium efficiency wage under whatever conditions, and at the same time makes the central government's constraint to incentivize the local official to exert effort easier to be satisfied under some conditions, while harder to be satisfied under other conditions.
\end{abstract}

Keywords: media capture, government accountability, moral hazard, efficiency wage, central government, local government

JEL Classification: D72, D73, L82

\section{Introduction}

Generally speaking, the mass media have a tremendous impact on collective decisionmaking (Stromberg, 2001; Corneo, 2006), although the news organization's internal structure and market forces are critical determinants of their power over public opinion (Bovitz et al., 2002). In this paper, we analyze the effects of media capture on local government accountability in undemocratic countries through an incentive theoretical approach. When there is no media capture, the local official will restrain himself, and seldom misbehaves. However, when there is media capture, the local official will be unbridled, and usually misbehaves. Although the media play an important role in local government accountability, there is no related literature on their functioning mechanism when the media are controlled by the central government, especially in those undemocratic countries. We do not try to explain the reason why the features of the media market determine the ability of the government to exercise such capture and hence to influence political outcomes, just as Besley and Prat (2006) do, but we try to extend their analysis to the case of politically centralized but economically decentralized countries (e.g., China) through a very different approach. In these countries, voters' ballots play a trivial role for the local official to retain his post, while

* Jiancai Pi, Department of Economics, School of Business, Nanjing University, 22 Hankou Road, 210093 Nanjing, China (pi2008@nju.edu.cn, jincaipi@hotmail.com). 
the central government's appointment plays a crucial role, which is greatly different from the well-known canonical political agency model (Barro, 1973; Ferejohn, 1986).

Certainly, as for undemocratic countries, almost all the media are controlled by the central authorities in a unified way, and at the same time the local media are strictly administered by the local governments who are in charge of them. There is interregional media monitoring, as different media are in charge by different local governments, which will alleviate media capture to some degree. The central government is responsive to popular resentment toward the malfeasant local officials, and this kind of responsiveness is just like what Besley and Burgess $(2002,2003)$ have analyzed. As for the local official, once his misbehavior is reported by the media, he will almost have no chance to be promoted to a higher position.

Our basic idea is that for an undemocratic country, media capture is caused by the central government's censorship, and that the media can be used by the central government to monitor the local governments. That is to say, to capture the media or not can act as a feasible strategy for the central government to oversee the local governments, however, not to capture the media will incur some expected social instability cost to the central government. For analytical simplicity, we do not consider other kinds of media capture, such as media capture by the local officials, in which the local officials bribe the reporters in exchange for promises not to reveal their misbehavior. There is some evidence which supports our main motivation. For example, in China, as the degree of economic decentralization becomes higher and higher, the degree of media freedom does not change at the same level. In fact, the degree of media freedom is controlled by the central government firmly, which often issues censorship guidelines to the mass media, and local governments do not have this kind of censorship right at all.

In order to convey our idea, we assume that the central government is benevolent, who decides the local officials' careers and prospects. When the media are captured by the central government, local officials do not have the incentive to exert productive effort. When the central government censors the media strictly, the media are captured totally, which does good to local officials. However, when the central government censors the media loosely, the media are captured partially, which does harm to local officials. For the sake of social stability, the central government generally censors the media between strictly and loosely according to its domestic political and economic situation. We try to conduct a comparative analysis of the central government's effects on local officials when the central government chooses different censorial strategies, to capture the media or not to capture the media.

The rest of the paper is organized as follows. Sections 2 and 3 offer the model with and without media capture. Section 4 conducts a comparative analysis of the two distinctive models. Section 5 extends the basic models. Section 6 provides some concluding remarks.

\section{The Model with Media Capture}

In this section, we follow Laffont and Martimort's (2002) analytical framework. In order to make their benchmark tool be suitable for our analysis, we modify some parameters and introduce some new variables. It is assumed that the local official is 
risk-neutral. When the local official exerts discrete productive effort level $e \in\{0,1\}$, the social added-value will be $\bar{V}>0$ with probability $\pi(e)$, and $\underline{V}>0$ with probability $1-\pi(e) . \bar{V}$ and $\underline{V}$ represent the values realized in the case of success and failure, respectively. $\pi(1)$ denotes the success probability when the local official expends effort, and $1-\pi(1)$ denotes the failure probability when the local official expends effort. That is to say, $\pi(1)=\operatorname{Pr}(V=\bar{V} \mid e=1)$. Similarly, $\pi(0)$ stands for the success probability when the local official does not spend effort, and $1-\pi(0)$ stands for the failure probability when the local official does not spend effort. That is to say, $\pi(0)=\operatorname{Pr}(V=\bar{V} \mid e=0)$. $\pi(1)>\pi(0)$ means that the success probability becomes bigger when the local official chooses to work harder. When the local official's performance is good, he can get a bonus, however, when his performance is bad, he will get no punishment. That is to say, he faces limited liability. When there is media capture, the local official's moral hazard is very difficult to be detected. For the sake of analytical simplicity, we neglect the role of the internal control mechanism of the central government which aims at assessing local officials' proficiency. When the local official does not exert productive effort, his effort cost is $\Psi_{0}^{C}=0$. When he exerts productive effort, his effort cost is $\Psi_{1}^{C}=\Psi>0$. The superscript $C$ denotes media capture. The subscripts 0 and 1 represent $e=0$ and $e=1$, respectively. The following mathematical definitions should be noted, $\pi(1)=\pi_{1}\left(0<\pi_{1}<1\right), \pi(0)=\pi_{0}\left(0<\pi_{0}<1\right), \Delta \pi=\pi_{1}-\pi_{0}>0$, $\Delta V=\bar{V}-V>0$.

In order to make the local official spend effort, the central government must find an optimal compensation plan $\{(\underline{t}, \bar{t})\}$. Under this plan, the central government's programming problem will be:

$$
\begin{array}{cc} 
& \max _{\{(\underline{t}, \bar{t})\}} \pi_{1}(\bar{V}-\bar{t})+\left(1-\pi_{1}\right)(\underline{V}-\underline{t}) \\
\text { s.t. } \quad & \pi_{1} \bar{t}+\left(1-\pi_{1}\right) \underline{t}-\Psi \geq \pi_{0} \bar{t}+\left(1-\pi_{0}\right) \underline{t}, \\
\pi_{1} \bar{t}+\left(1-\pi_{1}\right) \underline{t}-\Psi \geq 0, \\
\underline{t} \geq 0 .
\end{array}
$$

(1), (2), and (3) are the local official's incentive compatibility, participation, and limited liability constraints, respectively.

Solving this programming problem, we obtain:

$$
\begin{gathered}
\underline{t}^{C^{*}}=0, \\
\bar{t}^{C^{*}}=\frac{\Psi}{\Delta \pi} .
\end{gathered}
$$

The superscript $C^{*}$ stands for second-best state with media capture. $\bar{t}^{C^{*}}$ is the local official's equilibrium efficiency wage with media capture. We can find that this efficiency wage is positively related to effort cost and negatively related to the difference of success probabilities. 
In addition, we need to consider the central government's constraint to incentivize the local official to expend effort:

$$
\pi_{1}\left(\bar{V}-\frac{\Psi}{\Delta \pi}\right)+\left(1-\pi_{1}\right) \underline{V} \geq \pi_{0} \bar{V}+\left(1-\pi_{0}\right) \underline{V} .
$$

It is quite obvious that (6) can be simplified into:

$$
\Delta \pi \Delta V \geq \frac{\pi_{1} \Psi}{\Delta \pi} .
$$

Only when (7) is satisfied the central government has the incentive to make the local official exert effort.

\section{The Model without Media Capture}

When there is no media capture, the local official will be monitored by the media which he is not in charge of. When the local official does not expend productive effort, it is very easy to be detected by the media. So the local official's effort cost when he does not expend effort is $\Psi_{0}^{N}>0$. In other words, the media's monitoring will raise the local official's shirking cost, which brings about great inconvenience to the local official. $\Psi_{0}^{N}$ reflects this kind of inconvenience. When he exerts productive effort, his effort cost is $\Psi_{1}^{N}=\Psi>\Psi_{0}^{N}$. That is to say, $\Psi_{1}^{C}=\Psi_{1}^{N}=\Psi$. The superscript $N$ denotes no media capture. However, when there is no media capture, some social instability cost $c \geq 0$ will be incurred to the central government with probability $0 \leq \rho \leq 1$. In fact, we can use $\rho$ as a variable to delineate the types of local governments. Specifically, different types of local governments bring different $\rho \mathrm{s}$ to the central government.

The central government's new programming problem with no media capture will become:

$$
\begin{gathered}
\max _{\{(\underline{t}, \bar{t})\}} \pi_{1}(\bar{V}-\bar{t}-\rho c)+\left(1-\pi_{1}\right)(\underline{V}-\underline{t}-\rho c) \\
\text { s.t. } \pi_{1} \bar{t}+\left(1-\pi_{1}\right) \underline{t}-\Psi \geq \pi_{0} \bar{t}+\left(1-\pi_{0}\right) \underline{t}-\Psi_{0}^{N}, \\
\pi_{1} \bar{t}+\left(1-\pi_{1}\right) \underline{t}-\Psi \geq 0, \\
\underline{t} \geq 0 .
\end{gathered}
$$

(8), (9), and (10) are the local official's new incentive compatibility, participation, limited liability constraints, respectively. In order to neglect the local official's new participation constraint when he exerts no effort $\left(\pi_{0} \bar{t}+\left(1-\pi_{0}\right) \underline{t}-\Psi_{0}^{N} \geq 0\right)$, we assume that $\frac{\Psi_{0}^{N}}{\pi_{0}} \leq \min \left\{\frac{\Psi-\Psi_{0}^{N}}{\Delta \pi}, \frac{\Psi}{\pi_{1}}\right\}$ or $\min \left\{\frac{\Psi-\Psi_{0}^{N}}{\Delta \pi}, \frac{\Psi}{\pi_{1}}\right\}<\frac{\Psi_{0}^{N}}{\pi_{0}} \leq \max \left\{\frac{\Psi-\Psi_{0}^{N}}{\Delta \pi}, \frac{\Psi}{\pi_{1}}\right\}$. 
Solving this new programming problem, we obtain:

$$
\begin{gathered}
\text { If } \Psi \geq \frac{\pi_{1}}{\pi_{0}} \Psi_{0}^{N}, \text { then } \\
\underline{t}^{N^{*}}=0, \\
\bar{t}^{N^{*}}=\frac{\Psi-\Psi_{0}^{N}}{\Delta \pi} . \\
\text { If } \Psi<\frac{\pi_{1}}{\pi_{0}} \Psi_{0}^{N}, \text { then } \\
\underline{t}^{N^{*}}=0, \\
\bar{t}^{N^{*}}=\frac{\Psi}{\pi_{1}} .
\end{gathered}
$$

The superscript $N^{*}$ represents second-best state with no media capture. $\bar{t}^{N^{*}}$ is the local official's equilibrium efficiency wage with no media capture, which is obviously different from that with media capture.

If $\Psi \geq \frac{\pi_{1}}{\pi_{0}} \Psi_{0}^{N}$, the central government's constraint to incentivize the local official to spend effort will be:

$$
\pi_{1}\left(\bar{V}-\frac{\Psi-\Psi_{0}^{N}}{\Delta \pi}-\rho c\right)+\left(1-\pi_{1}\right)(\underline{V}-\rho c) \geq \pi_{0} \bar{V}+\left(1-\pi_{0}\right) \underline{V} .
$$

It is quite obvious that (15) can be simplified into:

$$
\Delta \pi \Delta V \geq \frac{\pi_{1}\left(\Psi-\Psi_{0}^{N}\right)}{\Delta \pi}+\rho c
$$

If $\Psi<\frac{\pi_{1}}{\pi_{0}} \Psi_{0}^{N}$, the central government's constraint to incentivize the local official to spend effort will be:

$$
\pi_{1}\left(\bar{V}-\frac{\Psi}{\pi_{1}}-\rho c\right)+\left(1-\pi_{1}\right)(\underline{V}-\rho c) \geq \pi_{0} \bar{V}+\left(1-\pi_{0}\right) \underline{V} .
$$

It is quite obvious that (17) can be simplified into:

$$
\Delta \pi \Delta V \geq \Psi+\rho c
$$

\section{A Comparative Analysis}

In this section, we will conduct a comparative analysis between the outcomes with media capture and with no media capture.

It is easy for us to obtain the following three propositions. 
Proposition 1: No media capture will decrease the local official's equilibrium efficiency wage. That is to say, $\bar{t}^{N^{*}}<\bar{t}^{C^{*}}$.

Proof: If $\Psi \geq \frac{\pi_{1}}{\pi_{0}} \Psi_{0}^{N}$, then from (7) and (12), we obtain:

$$
\bar{t}^{N^{*}}-\bar{t}^{C^{*}}=\frac{\Psi-\Psi_{0}^{N}}{\Delta \pi}-\frac{\Psi}{\Delta \pi}=-\frac{\Psi_{0}^{N}}{\Delta \pi}<0 .
$$

If $\Psi<\frac{\pi_{1}}{\pi_{0}} \Psi_{0}^{N}$, then from (7) and (14), we obtain:

$$
\bar{t}^{N^{*}}-\bar{t}^{C^{*}}=\frac{\Psi}{\pi_{1}}-\frac{\Psi}{\Delta \pi}=-\frac{\pi_{0} \Psi}{\pi_{1} \Delta \pi}<0 .
$$

Under whatever conditions, the local official's equilibrium efficiency wage will be decreased, provided there is no media capture. In other words, media capture will increase the local official's efficiency wage. The economic intuition of Proposition 1 is that the central government can control the degree of media capture at the cost of increasing the local official's equilibrium efficiency wage.

Proposition 2: When $\Psi \geq \frac{\pi_{1}}{\pi_{0}} \Psi_{0}^{N}$ and $\rho c<\frac{\pi_{1} \Psi_{0}^{N}}{\Delta \pi}$ or when $\Psi<\frac{\pi_{1}}{\pi_{0}} \Psi_{0}^{N}$ and $\rho c<\frac{\pi_{0} \Psi}{\Delta \pi}$, no media capture will make the central government's constraint to incentivize the local official to expend effort easier to be satisfied.

Proof: If $\Psi \geq \frac{\pi_{1}}{\pi_{0}} \Psi_{0}^{N}$ and $\rho c<\frac{\pi_{1} \Psi_{0}^{N}}{\Delta \pi}$, then from (7) and (16), we obtain:

$$
\frac{\pi_{1} \Psi}{\Delta \pi}-\left[\frac{\pi_{1}\left(\Psi-\Psi_{0}^{D}\right)}{\Delta \pi}+\rho c\right]=\frac{\pi_{1} \Psi_{0}^{N}}{\Delta \pi}-\rho c>0
$$

If $\Psi<\frac{\pi_{1}}{\pi_{0}} \Psi_{0}^{N}$ and $\rho c<\frac{\pi_{0} \Psi}{\Delta \pi}$, then from (7) and (18), we obtain:

$$
\frac{\pi_{1} \Psi}{\Delta \pi}-(\Psi+\rho c)=\frac{\pi_{0} \Psi}{\Delta \pi}-\rho c>0
$$

Proposition 3: When $\Psi \geq \frac{\pi_{1}}{\pi_{0}} \Psi_{0}^{N}$ and $\rho c>\frac{\pi_{1} \Psi_{0}^{N}}{\Delta \pi}$ or when $\Psi<\frac{\pi_{1}}{\pi_{0}} \Psi_{0}^{N}$ and $\rho c>\frac{\pi_{0} \Psi}{\Delta \pi}$, no media capture will make the central government's constraint to incentivize the local official to spend effort harder to be satisfied.

Proof: If $\Psi \geq \frac{\pi_{1}}{\pi_{0}} \Psi_{0}^{N}$ and $\rho c>\frac{\pi_{1} \Psi_{0}^{N}}{\Delta \pi}$, then from (7) and (16), we obtain: 


$$
\frac{\pi_{1} \Psi}{\Delta \pi}-\left[\frac{\pi_{1}\left(\Psi-\Psi_{0}^{D}\right)}{\Delta \pi}+\rho c\right]=\frac{\pi_{1} \Psi_{0}^{N}}{\Delta \pi}-\rho c<0
$$

If $\Psi<\frac{\pi_{1}}{\pi_{0}} \Psi_{0}^{N}$ and $\rho c>\frac{\pi_{0} \Psi}{\Delta \pi}$, then from (7) and (18), we obtain:

$$
\frac{\pi_{1} \Psi}{\Delta \pi}-(\Psi+\rho c)=\frac{\pi_{0} \Psi}{\Delta \pi}-\rho c<0
$$

When there is no media capture, the central government's constraint to incentivize the local official to spend effort will be easier to be satisfied under some conditions, while harder to be satisfied under other conditions. Although no media capture seems beneficial to the whole society, the central government has to make a trade-off between this kind of benefit and the expected cost of social instability. As $c$ and $\rho$ increase, the central government tends to capture the media, otherwise it tends not to capture the media. As long as the central government takes it for granted that the undisclosed truth plays an important role in its stable and legitimate ruling, it will not cancel the regulation in media, which will result in complete or partial media capture. For analytical simplicity, in this paper we do not consider the well-known media scrutiny paradox, which holds that the quality of office holders falls if the selection effect is adverse and outweighs the screening effect (Sutter, 2006).

In some undemocratic countries, the central government tries to differentiate between economic news and political news, and hence between economic effort and political effort. Therefore, there may exist different optimal degrees of media capture according to different kinds of effort. Certainly, media outlets in those countries have the incentive to push the coverage to the edge of censorship in order to attract as many readers as possible, and this may give rise to persistent media bias (Baron, 2006), especially in undemocratic countries.

\section{An Extension}

In this section, we consider the case that there is externality. When there is no media capture, the existence of the mass media decreases the local official's success probability $\pi_{1}$ to $\pi_{1}^{\prime}$, where $\pi_{1}^{\prime}<\pi_{1}$. That is to say, when the local official exerts effort, the mass media will do some harm to him which produces a putting-backward effect. The intuition behind this kind of externality is as follows. The local official may exert effort at the expense of national macroeconomic stability or jurisdictional environmental cleanness. When this kind of behavior is reported by the mass media, the local official's success probability will be reduced.

In this case, the extended programming problem without media capture will become:

$$
\begin{array}{cc} 
& \max _{\{(\underline{t}, \bar{t})\}} \pi_{1}^{\prime}(\bar{V}-\bar{t}-\rho c)+\left(1-\pi_{1}^{\prime}\right)(\underline{V}-\underline{t}-\rho c) \\
\text { s.t. } & \pi_{1}^{\prime} \bar{t}+\left(1-\pi_{1}^{\prime}\right) \underline{t}-\Psi \geq \pi_{0} \bar{t}+\left(1-\pi_{0}\right) \underline{t}-\Psi_{0}^{N},
\end{array}
$$




$$
\begin{gathered}
\pi_{1}^{\prime} \bar{t}+\left(1-\pi_{1}^{\prime}\right) \underline{t}-\Psi \geq 0, \\
\underline{t} \geq 0 .
\end{gathered}
$$

(19), (20), and (21) are the local official's extended incentive compatibility, participation, and limited liability constraints, respectively. In order to neglect the local official's extended participation constraint when he exerts no effort $\left(\pi_{0} \bar{t}+\left(1-\pi_{0}\right) \underline{t}-\Psi_{0}^{N} \geq 0\right)$, we assume that $\frac{\Psi_{0}^{N}}{\pi_{0}} \leq \min \left\{\frac{\Psi-\Psi_{0}^{N}}{\Delta \pi}, \frac{\Psi}{\pi_{1}}\right\}$ or $\min \left\{\frac{\Psi-\Psi_{0}^{N}}{\Delta \pi}, \frac{\Psi}{\pi_{1}}\right\}<\frac{\Psi_{0}^{N}}{\pi_{0}} \leq \max \left\{\frac{\Psi-\Psi_{0}^{N}}{\Delta \pi}, \frac{\Psi}{\pi_{1}}\right\} . "$

Solving this extended programming problem, we obtain:

$$
\begin{gathered}
\text { If } \Psi \geq \frac{\pi_{1}^{\prime}}{\pi_{0}} \Psi_{0}^{N}, \text { then } \\
\underline{t}^{N E^{*}}=0, \\
\bar{t}^{N E^{*}}=\frac{\Psi-\Psi_{0}^{D}}{\Delta \pi^{\prime}} . \\
\text { If } \Psi<\frac{\pi_{1}^{\prime}}{\pi_{0}} \Psi_{0}^{N}, \text { then } \\
\underline{t}^{N E^{*}}=0, \\
\bar{t}^{N E^{*}}=\frac{\Psi}{\pi_{1}^{\prime}} .
\end{gathered}
$$

The superscript $N E^{*}$ stands for second-best state without media capture and with externality. $t^{N E^{*}}$ is the local official's equilibrium efficiency wage without media capture but with externality. $\Delta \pi^{\prime}=\pi_{1}^{\prime}-\pi_{0}>0$. By comparison, it is easy for us to find that $\Delta \pi^{\prime} \leq \Delta \pi$.

If $\Psi \geq \frac{\pi_{1}^{\prime}}{\pi_{0}} \Psi_{0}^{N}$, then the central government's constraint to incentivize the local official will be:

$$
\pi_{1}^{\prime}\left(\bar{V}-\frac{\Psi-\Psi_{0}^{D}}{\Delta \pi}-\rho c\right)+\left(1-\pi_{1}^{\prime}\right)(\underline{V}-\rho c) \geq \pi_{0} \bar{V}+\left(1-\pi_{0}\right) \underline{V} .
$$

It is quite obvious that (26) can be simplified into:

$$
\Delta V \geq \frac{\pi_{1}^{\prime}\left(\Psi-\Psi_{0}^{N}\right)}{\left(\Delta \pi^{\prime}\right)^{2}}+\frac{\rho c}{\Delta \pi^{\prime}} .
$$


If $\Psi<\frac{\pi_{1}^{\prime}}{\pi_{0}} \Psi_{0}^{N}$, then the central government's constraint to incentivize the local official will be:

$$
\pi_{1}^{\prime}\left(\bar{V}-\frac{\Psi}{\pi_{1}^{\prime}}-\rho c\right)+\left(1-\pi_{1}^{\prime}\right)(\underline{V}-\rho c) \geq \pi_{0} \bar{V}+\left(1-\pi_{0}\right) \underline{V} .
$$

It is quite obvious that (28) can be simplified into:

$$
\Delta V \geq \frac{\Psi+\rho c}{\Delta \pi^{\prime}}
$$

When we conduct a comparative analysis between the outcomes with media capture and that without media capture but with externality, it is easy for us to obtain the following two propositions.

Proposition 4: If there exists externality, no media capture will decrease the local official's equilibrium efficiency wage when $\frac{\pi_{1}^{\prime}}{\pi_{0}} \Psi_{0}^{N} \leq \Psi \leq \frac{\Delta \pi}{\Delta \pi-\Delta \pi^{\prime}} \Psi_{0}^{N}$ or when $\Psi<\frac{\pi_{1}^{\prime}}{\pi_{0}} \Psi_{0}^{N}$ and $\Delta \pi \leq \pi_{1}^{\prime}$.

Proof: When $\frac{\pi_{1}^{\prime}}{\pi_{0}} \Psi_{0}^{N} \leq \Psi \leq \frac{\Delta \pi}{\Delta \pi-\Delta \pi^{\prime}} \Psi_{0}^{N}$, then from (5) and (23), we obtain:

$$
\bar{t}^{N E^{*}}-\bar{t}^{N^{*}}=\frac{\Psi-\Psi_{0}^{N}}{\Delta \pi^{\prime}}-\frac{\Psi}{\Delta \pi}=\left(\frac{1}{\Delta \pi^{\prime}}-\frac{1}{\Delta \pi}\right) \Psi-\frac{\Psi_{0}^{N}}{\Delta \pi^{\prime}} \leq 0 .
$$

When $\Psi<\frac{\pi_{1}^{\prime}}{\pi_{0}} \Psi_{0}^{N}$ and $\Delta \pi \leq \pi_{1}^{\prime}$, then from (5) and (25), we obtain:

$$
\bar{t}^{N E^{*}}-\bar{t}^{N^{*}}=\frac{\Psi}{\pi_{1}^{\prime}}-\frac{\Psi}{\Delta \pi} \leq 0
$$

Remark 1: Comparing Proposition 4 with Proposition 1, we can find that externality does affect the conditions under which no media capture decreases the local official's equilibrium efficiency wage. The more externality there is, the more uncertain the decrease effect in Propositions 1 and 4.

Proposition 5: If there is externality, no media capture will make the central government's constraint to incentivize the local official easier to be satisfied when

$$
\begin{gathered}
\Psi \geq \frac{\pi_{1}^{\prime}}{\pi_{0}} \Psi_{0}^{N} \text { and } \rho c<\frac{\pi_{1} \Delta \pi \Psi}{(\Delta \pi)^{2}}-\frac{\pi_{1}^{\prime}\left(\Psi-\Psi_{0}^{N}\right)}{\Delta \pi^{\prime}} \text { or when } \Psi<\frac{\pi_{1}^{\prime}}{\pi_{0}} \Psi_{0}^{N} \text { and } \\
\rho c<\frac{\pi_{1} \Delta \pi^{\prime}-(\Delta \pi)^{2}}{(\Delta \pi)^{2}} \Psi .
\end{gathered}
$$


Proof: When $\Psi \geq \frac{\pi_{1}^{\prime}}{\pi_{0}} \Psi_{0}^{N}$ and $\rho c<\frac{\pi_{1} \Delta \pi \Psi}{(\Delta \pi)^{2}}-\frac{\pi_{1}^{\prime}\left(\Psi-\Psi_{0}^{N}\right)}{\Delta \pi^{\prime}}$, then from (7) and (27), reminding that (7) can be transformed to $\Delta V \geq \frac{\pi_{1} \Psi}{(\Delta \pi)^{2}}$, we obtain:

$$
\frac{\pi_{1} \Psi}{(\Delta \pi)^{2}}-\left[\frac{\pi_{1}^{\prime}\left(\Psi-\Psi_{0}^{N}\right)}{\left(\Delta \pi^{\prime}\right)^{2}}+\frac{\rho c}{\Delta \pi^{\prime}}\right]=\frac{1}{\Delta \pi^{\prime}}\left[\frac{\pi_{1} \Delta \pi \Psi}{(\Delta \pi)^{2}}-\frac{\pi_{1}^{\prime}\left(\Psi-\Psi_{0}^{N}\right)}{\Delta \pi^{\prime}}-\rho c\right]>0 .
$$

When $\Psi<\frac{\pi_{1}^{\prime}}{\pi_{0}} \Psi_{0}^{N}$ and $\rho c<\frac{\pi_{1} \Delta \pi^{\prime}-(\Delta \pi)^{2}}{(\Delta \pi)^{2}} \Psi$, then from (7) and (29), reminding that (7) can be transformed to $\Delta V \geq \frac{\pi_{1} \Psi}{(\Delta \pi)^{2}}$, we obtain:

$$
\frac{\pi_{1} \Psi}{(\Delta \pi)^{2}}-\frac{\Psi+\rho c}{\Delta \pi^{\prime}}=\frac{1}{\Delta \pi^{\prime}}\left[\frac{\pi_{1} \Delta \pi^{\prime}-(\Delta \pi)^{2}}{(\Delta \pi)^{2}} \Psi-\rho c\right]>0 .
$$

Remark 2: Comparing Proposition 5 with Proposition 2, we can find that externality does play an important role in determining the conditions under which the central government has the incentive to motivate the local official, and that it does make the problem more complex and more subtle for us to tackle.

Our extension is based on a case that is more real-life where $\pi_{1}^{\prime}<\pi_{1}$ and $\pi_{0}{ }^{\prime}=\pi_{0}$. Theoretically, there may exist other cases that $\pi_{1} \leq \pi_{1}^{\prime}$ and $\pi_{0} \leq \pi_{0}{ }^{\prime}$ or $\pi_{1} \geq \pi_{1}^{\prime}$ and $\pi_{0} \geq \pi_{0}^{\prime}$ or $\pi_{1} \geq \pi_{1}^{\prime}$ and $\pi_{0} \leq \pi_{0}^{\prime}$. Our analytical framework can also analyze all these cases. However, in order to make our analyses be of real-life interest, we intentionally neglect these uninteresting cases.

\section{Conclusion}

In order to analyze the conflicting effects of media capture, we conduct a comparative analysis between the outcomes with and without media capture. The analysis shows that media capture will enhance the local official's equilibrium efficiency wage, and at the same time make the central government's constraint to incentivize the local official to exert effort easier to be satisfied under some conditions, while harder to be satisfied under other conditions. In a word, media capture does harm to the whole society, but as for an undemocratic country it can bring about social stability, so the central government has to make a trade-off between the benefit and cost. Because these undemocratic countries are different from democracies in political institutions, the causes of their media capture are fundamentally different, too. Although a free press is a bad news for corruption (Brunetti and Weder, 2003), it is also a bad news for social stability in some undemocratic countries. Just as Djankov et al. (2003) support that government ownership of the media undermines political and economic freedom, our analysis shows that this is because undemocratic countries are afraid of social 
instability resulting from people's resentment toward misbehaving local officials which will challenge their ruling legitimacy to some extent. Our contribution is that we find out the effects of media capture on local government accountability in undemocratic countries.

We should consider the implicit conditions of a country when we undertake related theoretical analyses, and we think this short paper is an attempt to find some undemocratic countries' implicit conditions which should not be ignored. As for democratic countries, media capture is mainly caused by influential interest groups (e.g., Corneo, 2006; Petrova, 2008; Chan and Suen, 2009), and local governments are accountable for jurisdictional residents. However, as for undemocratic countries, media capture mainly arises from the central government, and local governments are responsible for the central government.

\section{References}

Baron, D. (2006), "Persistent Media Bias." Journal of Public Economics, Vol. 90, pp. 1-36.

Barro, R. (1973), "The Control of Politicians: An Economic Model." Public Choice, Vol. 14, pp. 19-42.

Besley, T., Burgess, R. (2002), "The Political Economy of Government Responsiveness: Theory and Evidence from India." Quarterly Journal of Economics, Vol. 117, pp. 1415-1451.

Besley, T., Burgess, R. (2003), "Political Agency, Government Responsiveness, and the Role of Media." European Economic Review, Vol. 45, pp. 629-640.

Besley, T., Prat, A. (2006), "Handcuffs for the Grabbing Hand? Media Capture and Government Accountability." American Economic Review, Vol. 96, pp. 720-736.

Bovitz, G. L., Druckman, J. N., Lupia, A. (2002), "When Can a News Organization Lead Public Opinion? Ideology versus Market Forces in Decisions to Make News." Public Choice, Vol. 113, pp. 127-155.

Brunetti, A., Weder, B. (2003), "A Free Press Is Bad News for Corruption." Journal of Public Economics, Vol. 87, pp. 1801-1824.

Chan, J., Suen, W. (2009), "Media as Watchdogs: The Role of News Media in Electoral Competition." European Economic Review, Vol. 53, pp. 799-814.

Corneo, G. (2006), "Media Capture in a Democracy: The Role of Wealth Concentration." Journal of Public Economics, Vol. 90, pp. 37-58.

Djakov, S., McLeish, C., Nenova, T., Shleifer, A. (2003), "Who Owns the Media?" Journal of Law and Economics, Vol. 46, pp. 341-382.

Ferejohn, J. (1986), "Incumbent Performance and Electoral Control." Public Choice, Vol. 50, pp. 5-25.

Laffont, J.-J., Martimort, D. (2002), The Theory of Incentives. Princeton University Press, New Jersey.

Petrova, M. (2008), "Inequality and Media Capture." Journal of Public Economics, Vol. 92, pp. 183-212.

Stromberg, D. (2001), "Mass Media and Public Policy." European Economic Review, Vol. 45, pp. 652-663.

Sutter, D. (2006), "Media Scrutiny and the Quality of Public Officials." Public Choice, Vol. 129, pp. 25-40. 